\title{
Local Delivery of Dexamethasone for Prevention of Neointimal Proliferation in a Rat Model of Balloon Angioplasty
}

\author{
Augusto E. Villa, Luis A. Guzman, Weiliam Chen, * Gershon Golomb, * Robert J. Levy, * and Eric J. Topol \\ Department of Cardiology, Center for Thrombosis and Vascular Biology, The Cleveland Clinic Foundation, Cleveland, Ohio 44195; and \\ * Division of Pediatric Cardiology, University of Michigan Medical School, Ann Arbor, Michigan 48109
}

\begin{abstract}
A periadventitial polymer system is an alternative local drug delivery technique to obtain and maintain high tissue levels of the drug at the site of vascular injury. To determine if local periadventitial delivery of dexamethasone decreases neointimal proliferation after balloon vascular injury, in three groups of Sprague-Dawley rats, $5 \%$ dexamethasone, $0.5 \%$ dexamethasone, and placebo silicone polymers were implanted around the left common carotid artery after balloon injury. In a fourth group, placebo polymers were implanted without balloon injury. Dexamethasone serum and tissue levels after polymer implantation were significantly higher in the 5\% dexamethasone group compared with the $0.5 \%$ dexamethasone group. There was no neointima formation in any of the arterial segments covered with placebo polymers for 3 wk, but without balloon injury. In the arterial segments covered by the 5 and $0.5 \%$ dexamethasone polymers, there was a 76 and $75 \%$ reduction in intima/media ratios, respectively, compared with the placebo group ( $5 \%$ dexamethasone, $0.26 \pm 0.04 ; 0.5 \%$ dexamethasone, $0.27 \pm 0.03$; placebo, 1.09 \pm 0.16 , respectively; $P<0.0001$ ). These results suggest that: $(a)$ silicone polymers wrapped around the common carotid arteries for 3 wk did not, without balloon injury, stimulate neointimal proliferation in the rat model; (b) the activity of the drug-eluting polymer for suppressing intimal proliferation was chiefly, but not exclusively, site specific; and (c) transadventitial local delivery of dexamethasone at two different doses markedly inhibits neointimal proliferation after balloon vascular injury. (J. Clin. Invest. 1994. 93:1243-1249.) Key words: glucocorticoids • restenosis • balloon angioplasty $\bullet$ rat carotid model $\bullet$ polymer
\end{abstract}

\section{Introduction}

While percutaneous balloon angioplasty has become an important tool in the management of coronary artery disease, restenosis in at least $30-50 \%$ of cases remains the major limiting factor of long-term efficacy (1-3). Several pharmacological agents have been shown to decrease intimal proliferation after balloon injury when administered systemically in different animal models (4-6). However, when these drugs have been tested in clini-

Address correspondence to Dr. Eric J. Topol, Department of Cardiology, The Cleveland Clinic Foundation, 9500 Euclid Avenue, Cleveland, $\mathrm{OH}$ 44195-5066.

Received for publication 18 May 1993 and in revised form 28 September 1993.

J. Clin. Invest.

(c) The American Society for Clinical Investigation, Inc.

$0021-9738 / 94 / 03 / 1243 / 07 \quad \$ 2.00$

Volume 93, March 1994, 1243-1249 cal trials, benefit has not yet been confirmed (7-10). An important possible explanation is the difference in drug dose administered; most of the animal experiments were done with doses at least an order of magnitude higher than the same drugs used in clinical trials. Furthermore, there is difficulty in providing controlled administration of the drugs for an adequate period of time. Newer approaches for a more effective site-specific drug delivery are being directed toward local delivery systems rather than systemic drug administration in an attempt to achieve and sustain high tissue levels of the drug at the site of balloon injury, and decrease or avoid the potential adverse systemic side effects.

Several local drug delivery systems, including different perfusion balloon catheters, hydrogel-coated balloon catheters, and biodegradable polymer-coated metallic stents, are currently under investigation (11-16). However, due to the vessel size in small animals, these devices cannot be used for intraluminal local drug delivery. An alternative technique is the use of periadventitial polymer systems, which can be impregnated with different drugs $(17,18)$. This technique may permit the in vivo identification of agents that will inhibit neointimal proliferation after local delivery at the site of vascular injury. Okada et al. (19) and Edelman et al. (20), using two different periadventitial polymer continuous release systems to deliver heparin at the site of balloon injury, were able to inhibit intimal proliferation without producing systemic anticoagulation in the rat carotid model.

We used nondegradable silicone rubber polymers, not previously used in any restenosis studies, because they offer high biocompatibility and hydrophobicity linked to excellent sustained release properties (21). Dexamethasone was tested because of its well-known potent antiinflammatory effect (22). Within several days after balloon angioplasty, inflammatory cells are present at the site of arterial wall injury (23-26); these cells are an important source of cytokine production for smooth muscle cell migration and proliferation (27). Glucocorticoids have also been shown to inhibit smooth muscle cell proliferation in vitro (28-30), and significantly decrease neointimal proliferation in vivo after administration of high systemic doses for 7-14 d (31-33). Dexamethasone, however, is a most potent glucocorticoid, and thus is ideally suited for local drug-polymer administration, where potency must be optimized due to obvious physical restrictions. Local dexamethasone has not been previously investigated for prevention of restenosis. This study was designed to test our hypothesis that local adventitial dexamethasone delivery will decrease neointimal proliferation after balloon injury in the rat carotid model.

\section{Methods}

In 3 groups of male Sprague-Dawley rats, weighing $350-450 \mathrm{~g}, 10$ silicone polymer matrices loaded with $5 \%$ dexamethasone, 11 silicone 
polymer matrices loaded with $0.5 \%$ dexamethasone, and 10 placebo silicone polymer matrices were implanted around the left common carotid arteries after deendothelialization with a 2-French Fogarty balloon catheter (Baxter Healthcare Corp., Santa Ana, CA). In a fourth group of eight rats, placebo silicone polymer matrices were implanted without balloon deendothelialization, to determine if periadventitial placement of a polymer matrix by itself can induce neointimal proliferation. All animal experiments were performed according to the animal welfare policy of the American Heart Association and The Cleveland Clinic Foundation, and the experimental protocol was approved by the animal research committee.

Balloon injury technique and local delivery of dexamethasone. General anesthesia was induced with a mixture of ketamine $(80 \mathrm{mg} / \mathrm{kg}$ i.p. $)$ and xylazine $(5 \mathrm{mg} / \mathrm{kg}$ i.p.). Through a midline neck incision the left common, external, and internal carotid arteries were exposed by blunt dissection. A 2F Fogarty balloon catheter was introduced in the left external carotid artery via an arteriotomy and advanced to the origin of the left common carotid artery. The balloon was inflated sufficiently to generate slight resistance and withdrawn three times to consistently produce endothelial denudation of the entire length of the left common carotid artery. Upon removal of the catheter the left external carotid artery was ligated with 3.0 silk. After this, the left common carotid artery was covered circumferentially with a 15 -mm-long silicone polymer matrix, sealed on the external side to prevent release into adjacent tissue. The wound was closed with skin staples. $24 \mathrm{~h}$ after the polymer matrix implantation, a blood sample was obtained for determination of dexamethasone levels from the tail vein.

Death, pressure perfusion fixation, and histologic analysis. $3 \mathrm{wk}$ after balloon carotid injury, rats were anesthetized with a mixture of ketamine $(80 \mathrm{mg} / \mathrm{kg}$ i.p.) and xylazine $(5 \mathrm{mg} / \mathrm{kg}$ i.p.). Via a midline abdominal incision the distal abdominal aorta was exposed and a 18gauge intravenous catheter introduced above the aortic bifurcation. After a blood sample was obtained for determination of dexamethasone levels, the animals received a lethal dose of sodium pentobarbital. Both jugular veins were excised, and $50 \mathrm{~cm}^{3}$ of lactated ringer was infused at $120-\mathrm{mm} \mathrm{Hg}$ pressure into the abdominal aorta followed by pressure fixation with $200 \mathrm{~cm}^{3}$ of $10 \%$ formaldehyde solution infused over $5 \mathrm{~min}$ at $120-\mathrm{mm} \mathrm{Hg}$. After perfusion-fixation, the entire right and left carotid arteries were retrieved, including the aortic arch, innominate artery, and carotid bifurcation. The arteries were further fixed by immersion in the same fixative that was used for perfusion. The left commun carotid arteries were sectioned every $3 \mathrm{~mm}$ from the proximal to the distal ends. Three different sections of the left common carotid within the 15 -mm-long segment covered by the silicone polymer matrix and one section of the most proximal left common carotid artery not covered by the silicone polymer matrix were selected for histologic analysis (Fig. 1). These sections were embedded in paraffin for sectioning, and duplicate slides were stained with hematoxylin-eosin and Lawson's elastic-van Gieson.

Morphometric analysis was performed by an observer blinded to drug regimen using a computerized digital microscopic planimetry algorithm (Bioquant program). Cross sectional areas of media, intima and lumen were measured.

Analysis of two additional rats was performed in each dexamethasone group, killed $2 \mathrm{wk}$ after polymer matrix implantation for determination of dexamethasone arterial wall concentrations in the left common carotid artery segments covered by the polymer matrix, the adjacent segment not covered by the polymer matrix, and the contralateral arterial segment (right common carotid artery). Dexamethasone tissue and serum levels were measured directly by a radioimmunoassay (kindly performed by Dr. A. W. Meikle, University of Utah, Salt Lake City, UT).

Controlled release polymer matrices. The silicone rubber used in this study was Silastic Q74840 (Dow Corning Midland, MI). Controlled release matrices, in general, were formulated by sieving the desired agent as a dry powder to $90-120-\mu \mathrm{m}$ particle size, and levigating it with prevulcanized silicone rubber and exposing to vacuum for $30 \mathrm{~min}$. Polymerization techniques included casting the drug-polymer compos-

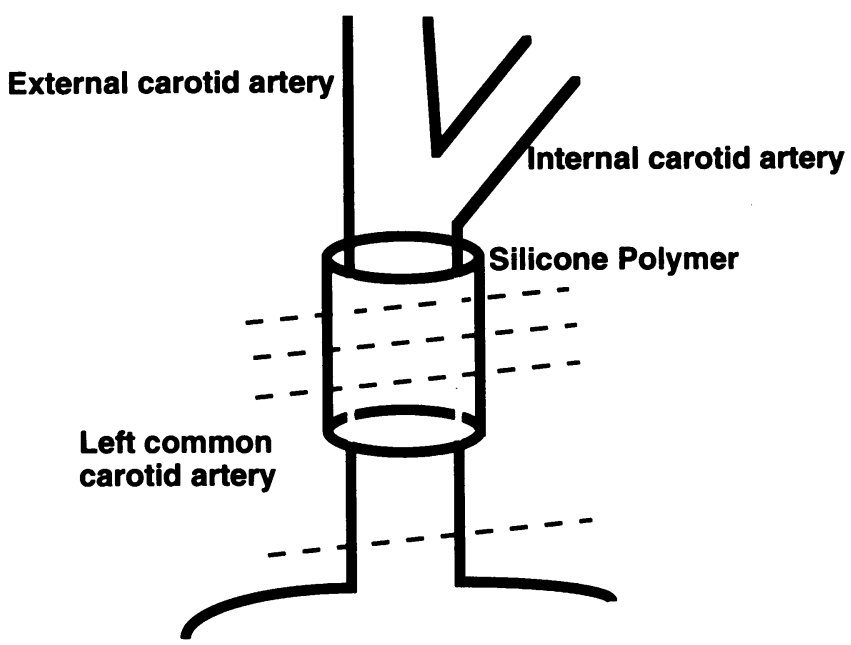

Figure 1. Illustration of the sections (dashed lines) of the left common carotid artery segment covered by the silicone polymer (three), and the segment not covered by the silicone polymer (one) selected for histologic and morphometric analysis.

ites into thin slabs in aluminum molds, under 20,000 psi in a press (Fred S. Carver Inc., Menomonee Falls, WI), and vulcanizing at $80^{\circ} \mathrm{C}$ for $50 \mathrm{~min}$. In addition, surfaces of slab matrices were sealed using the same silicone polymer in order to permit unidirectional drug release and limit swelling. In vitro drug release studies were carried out under perfect sink conditions at $\mathrm{pH} 7.4$ as previously published $(34,35)$.

Statistical analysis. All data are presented as the mean \pm SEM. Differences between the three groups were analyzed using an analysis of variance with Scheffe's test for post hoc comparisons. For differences between two groups a two-tailed, unpaired Student's $t$ test was used. Statistical significance was defined as $P<0.05$.

\section{Results}

Silicone polymer matrices. In vitro studies of the $5 \%$ dexamethasone-loaded silicone rubber controlled release matrices showed a constant drug release (zero-order kinetics) based on cumulative percentage of drug released after an initial 12-h burst phase (Fig. 2). The amount of dexamethasone contained in the silicone polymer matrices loaded with $5 \%$ of dexamethasone was $2.74 \pm 0.13 \mathrm{mg} / \mathrm{matrix}$, and in the matrices loaded with $0.5 \%$ of dexamethasone was $0.28 \pm 0.03 \mathrm{mg} /$ matrix $(P$ $=0.0001$ ).

Dexamethasone serum and tissue levels. Dexamethasone serum levels $24 \mathrm{~h}$ and $3 \mathrm{wk}$ after matrix implantation are shown in Fig. 3. In the 5\% dexamethasone group, serum levels were three times higher than in the $0.5 \%$ dexamethasone group $24 \mathrm{~h}$ after the implantation $(1,372 \pm 215$ vs. $452 \pm 197 \mathrm{ng} / \mathrm{dl}$, respectively; $P=0.01$ ). 3 wk later, serum levels decreased in both groups, but were still 2.3 times higher in the 5\% dexamethasone group compared with the $0.5 \%$ dexamethasone group ( $535 \pm 52$ vs. $233 \pm 31 \mathrm{ng} / \mathrm{dl}$, respectively; $P<0.001)$. It is also noted that dexamethasone serum levels in the controlled release animals were significantly higher after $24 \mathrm{~h}$ than at $3 \mathrm{wk}$. This is probably explained by the release kinetics of the polymer matrix (Fig. 2, see above), which results in an early burst effect of more rapid drug release during the first $24 \mathrm{~h}$ than the ensuing 3-wk releasing period. Dexamethasone serum levels were undetectable in the placebo group $24 \mathrm{~h}$ and $3 \mathrm{wk}$ after balloon injury and polymer implantation. 


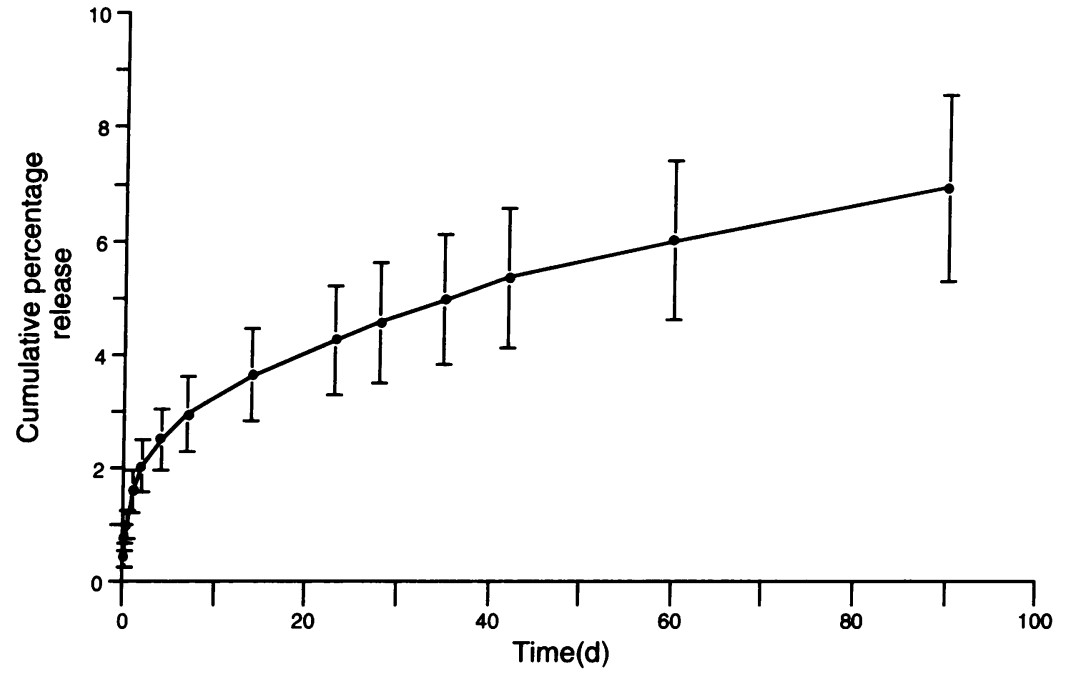

Figure 2. Graph showing cumulative dexamethasone ( $5 \%$ loaded) release as a percentage of the initial polymer loading from Q7-4840 rubber silicone polymers $(1 \times 1 \times 0.09$, one surface $)$ over an extended period. Each data point represents the mean of six matrices. Values are mean \pm SD.
Dexamethasone tissue levels 2 wk after polymer implantation, in the different arterial segments of both dexamethasone groups, are shown in Table I. Tissue levels in the covered segments of the 5\% dexamethasone group were 2.5 times higher than in the segments covered with $0.5 \%$ dexamethasone polymers. In the adjacent and contralateral segments, tissue levels were present but at much lower concentrations, thus demonstrating locally enhanced drug administration.

Neointimal proliferation. There was no neointima formation in any of the eight left common carotid artery segments that had no balloon deendothelialization injury, but were covered with a placebo silicone polymer matrix (Fig. 4).

Fig. $5 \mathrm{~A}$ shows the intima/media $(\mathrm{I} / \mathrm{M})^{1}$ ratio of the left common carotid artery segments covered with silicone matrices in the three groups that underwent balloon injury. The I/M ratios were very similar in both dexamethasone groups (dexamethasone 5\%, 0.264 \pm 0.036 ; dexamethasone $0.5 \%$, $0.273 \pm 0.031$ ), but significantly decreased compared with the placebo group ( $1.093 \pm 0.157)$. In the 5 and $0.5 \%$ dexamethasone groups, there was a 76 and $75 \%$ reduction in neointimal proliferation compared with the placebo group. The media cross sectional areas were similar in all three groups (dexamethasone $5 \%, 0.133 \pm 0.007 \mathrm{~mm}^{2}$; dexamethasone $0.5 \%$, $0.128 \pm 0.006 \mathrm{~mm}^{2}$; and placebo, $0.131 \pm 0.009 \mathrm{~mm}^{2}$ ).

Fig. $5 B$ shows the $\mathrm{I} / \mathrm{M}$ ratio of the left common carotid artery segments not covered with silicone polymer matrices in the three groups that underwent balloon injury. The I/M ratio in the dexamethasone 5\% group was decreased compared with the placebo group $(0.53 \pm 0.08$ vs. $1.1 \pm 0.21 ; P=0.01)$. However, the degree of inhibition in the noncovered arterial segments of the 5\% dexamethasone group was less pronounced than their respective polymer-covered segments, as demonstrated by a twofold difference $(0.53 \pm 0.08$ vs. $0.264 \pm 0.036$, respectively). There was no significant difference among the $0.5 \%$ dexamethasone and placebo groups $(0.81 \pm 0.07$ vs. $1.1 \pm 0.21 ; P=\mathrm{NS})$, or between the 0.5 and $5 \%$ dexamethasone groups $(0.81 \pm 0.07$ vs. $0.53 \pm 0.08 ; P=N S)$. The media cross sectional areas were similar in all three groups (dexamethasone $5 \%, 0.144 \pm 0.007 \mathrm{~mm}^{2}$; dexamethasone $0.5 \%, 0.137 \pm 0.008$ $\mathrm{mm}^{2}$; placebo, $0.152 \pm 0.01 \mathrm{~mm}^{2}$ ).

1. Ahbreviation used in this paper: $\mathrm{I} / \mathrm{M}$, intima/media.

\section{Discussion}

In this rat carotid model silicone polymers wrapped around the common carotid arteries for $3 \mathrm{wk}$ did not, without balloon injury, stimulate neointimal proliferation. Activity of the drugeluting polymer was chiefly, but not exclusively, site specific, and chronic local delivery of dexamethasone at two different doses markedly inhibited neointimal proliferation after balloon injury.

Periadventitial polymer matrix implantation. Previous observation of diffuse intimal thickening after temporary placing of a polyethylene cuff on the femoral arteries of rabbits (36) led us to investigate a group of rats in which placebo silicone matrices were wrapped around the left common carotid arteries, but no balloon deendothelialization injury was performed. $3 \mathrm{wk}$ after silicone polymer matrices placement, no neointimal formation was observed in any of the eight arterial segments covered. It remains possible that a longer period of time would be required in the rat carotid artery injury model to observe intimal thickening, in view of the fact that in the rabbit model previously described the intimal thickening reached its maximum at $12 \mathrm{wk}(36)$. However, these results suggest the possibil-

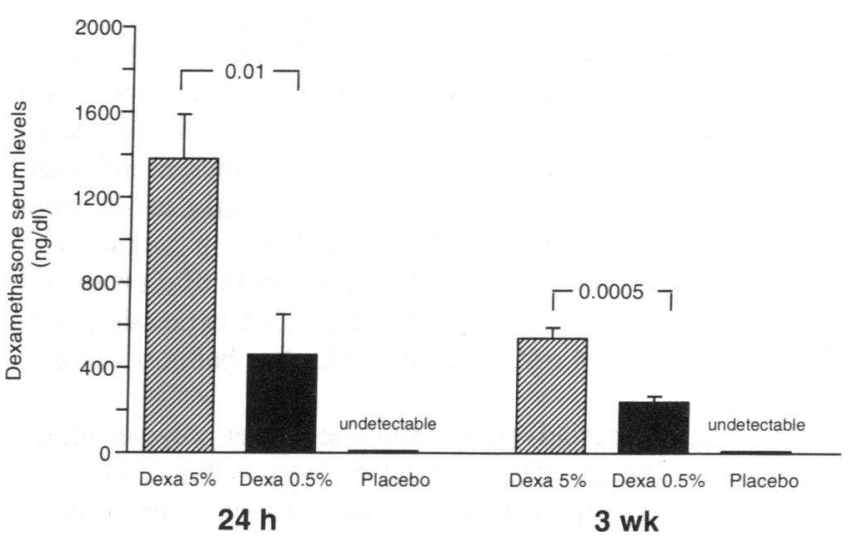

Figure 3. Bar graphs showing dexamethasone serum levels in the three groups of rats that underwent balloon injury $24 \mathrm{~h}$ and $3 \mathrm{wk}$ after polymer implantation. Values are mean \pm SEM. The $P$ values are shown between bars. 
Table I. Dexamethasone Arterial Wall Concentrations

\begin{tabular}{lcc}
\hline & $5 \%$ dexamethasone & $0.5 \%$ dexamethasone \\
\hline & \multicolumn{3}{c}{$n g / g$ tissue } \\
Covered segment & $880 \pm 220$ & $358 \pm 20$ \\
Adjacent segment & $168 \pm 71$ & $110 \pm 47$ \\
Contralateral segment & $147 \pm 87$ & $54 \pm 6$ \\
\hline
\end{tabular}

$5 \%$ dexamethasone, rat group treated with silicone polymers loaded with $5 \%$ dexamethasone; $0.5 \%$ dexamethasone, rat group treated with silicone polymers loaded with $0.5 \%$ dexamethasone; covered segment, left common carotid arterial segments covered with silicone polymer; adjacent segment, left common carotid arterial segments noncovered with silicone polymer; contralateral segment, right common carotid artery segments. All values are mean \pm SEM.

ity that the polymer matrices implanted loosely around the arteries did not occlude the adventitial vasa vasorum in this control group. Therefore, hypoxia of the outer media, the presumed mechanism initiating smooth muscle cell proliferation and migration with subsequent neointimal formation (37-39), may not have been induced in our study.

Local drug delivery. Attempts to deliver drugs at the site of balloon injury through balloon catheter systems have encountered difficulty in maintaining high local drug tissue concentrations for an adequate period of time (12, 40-42). This problem has prompted the use of controlled release drug delivery systems (18-20). Site-specific drug delivery has been extensively investigated in different animal models for the treatment of a number of specific cardiovascular disorders, including inhibition of cardiac arrhythmias (43) and bioprosthetic heart valve calcifications $(21,34,44)$, prevention of cardiac transplant rejection (45), and bacterial endocarditis on cardiac valve prostheses (46). In addition, one clinical trial has demonstrated the efficacy of site-specific therapy for optimization of the function of cardiac pacing leads (47).

In the rat carotid injury model, three different periadventitial polymer systems have been used for site-specific drug delivery. Okada et al. (19) first reported the use of $16 \%$ polyvinyl alcohol, a water-soluble, nontoxic polymer to deliver heparin periadventitial, enclosed in a silastic shell to prevent diffusion into surrounding tissue. Edelman et al. (20) initially administered heparin encapsulated in ethylene-vinyl acetate copolymer pellet matrices that were placed next to the injured carotid artery. Using this site of administration they inhibited neointimal proliferation after vascular injury. Subsequently, they were able to deliver successfully basic fibroblast growth factor into the arterial wall, using the same periadventitial delivery system $(48,49)$. Finally, Simons et al. (50) used a different polymer, the F-127 pluronic gel. This polymer that has the novel property of being soluble at $4^{\circ} \mathrm{C}$, while solidifying on contact with tissues at $37^{\circ} \mathrm{C}$. The periadventitial application of pluronic gel containing antisense c-myb inhibited mRNA expression of c$m y b$ and neointimal proliferation 2 wk after balloon vascular injury.

In our study, periadventitial silicone rubber polymer matrices proved to be an effective local delivery system capable of obtaining and maintaining significant tissue and serum dexamethasone levels for 2-3 wk after polymer matrix implantation. Previous work has demonstrated that very low percentage weight loading of steroids in silicone rubber resulted in effective controlled release through aqueous-polymer interface equi- librium phenomenon. This occurs secondarily to solid phase solution of dexamethasone in the dimethylpolysiloxane base polymer (51). The use of silicone rubbers, with enclosed hydrophobic drugs, is particularly advantageous in terms of voiding the hydrostatic swelling associated with water-soluble drugs dispersed in virtually any synthetic polymer. Dexamethasone and similar hydrophobic compounds form a solid phase solution in the silicone rubber coming to equilibrium with the extracellular fluid or plasma interface when implanted. This particular type of drug delivery system is obviously advantageous for an arterial implant, and has not been previously used in restenosis research.

The degree of growth inhibition in the segments covered by the silicone polymers was almost identical in both dexamethasone groups ( $76 \%$ inhibition in the $5 \%$ dexamethasone group vs. $75 \%$ in the $0.5 \%$ dexamethasone group), despite a much lower concentration of the drug in one of the groups, which was reflected also in the tissue and serum levels obtained. These data suggest that only a certain minimum amount of local drug concentration is required for growth inhibition, and higher concentrations will only raise the systemic levels with possible subsequent adverse systemic side effects of the drug. At higher local dexamethasone doses ( $5 \%$ group) a systemic effect of the drug was suggested by the significant inhibition of neointimal proliferation observed in the arterial segments not covered with silicone polymers. This effect was probably due to a systemic absorption of the drug as suggested by the tissue levels in the adjacent noncovered and contralateral arterial segments and the high serum levels. However, the degree of neointimal proliferation inhibition in the $5 \%$ dexamethasone-covered segments was more pronounced as evidenced by a twofold decrease in the I/M ratio compared with their respective noncovered arterial segments. This finding indicates an important local drug effect from the controlled release polymer in the covered segments of this $5 \%$ dexamethasone group. With lower dexamethasone doses ( $0.5 \%$ group), despite lower but significant dexamethasone systemic levels, the inhibition appeared to be site specific without a significant inhibition observed in the noncovered segments and tissue levels 3.3 times lower than in the covered segments.

Neointimal proliferation inhibition. Local delivery of dexamethasone via periadventitial silicone polymer matrix at two different doses for $3 \mathrm{wk}$ markedly inhibited neointimal proliferation after balloon injury in this rat carotid model.

Dexamethasone is a potent glucocorticoid that ideally should be administered locally at the site of balloon injury because of the deleterious side effects when administered systemically at high doses for a prolonged period of time. Glucocorticoids can inhibit restenosis through several possible mechanisms. They have a potent antiproliferative effect and have been shown to inhibit smooth cell proliferation in vitro (2830). This inhibition can be mediated through different mechanisms. First, glucocorticoids inhibit the autocrine production of PDGF A chain $(52,53)$. PDGF is a potent mitogen and important stimulus for migration of smooth muscle cells (54, $55)$. Second, glucocorticoids selectively inhibit the transcription of the IL- $\beta$ gene and decrease the stability of IL-1 $\beta$ mRNA (56). IL- $\beta$ is a cytokine that has been shown to stimulate smooth muscle cell proliferation $(57,58)$ and to induce basic fibroblast growth factor gene expression in human vascular smooth muscle cells (59). Third, glucocorticoids can repress the activity of c-Jun via downmodulation of transcriptional factor AP-1 activity (60-62). Jun/AP-1 is a member of 

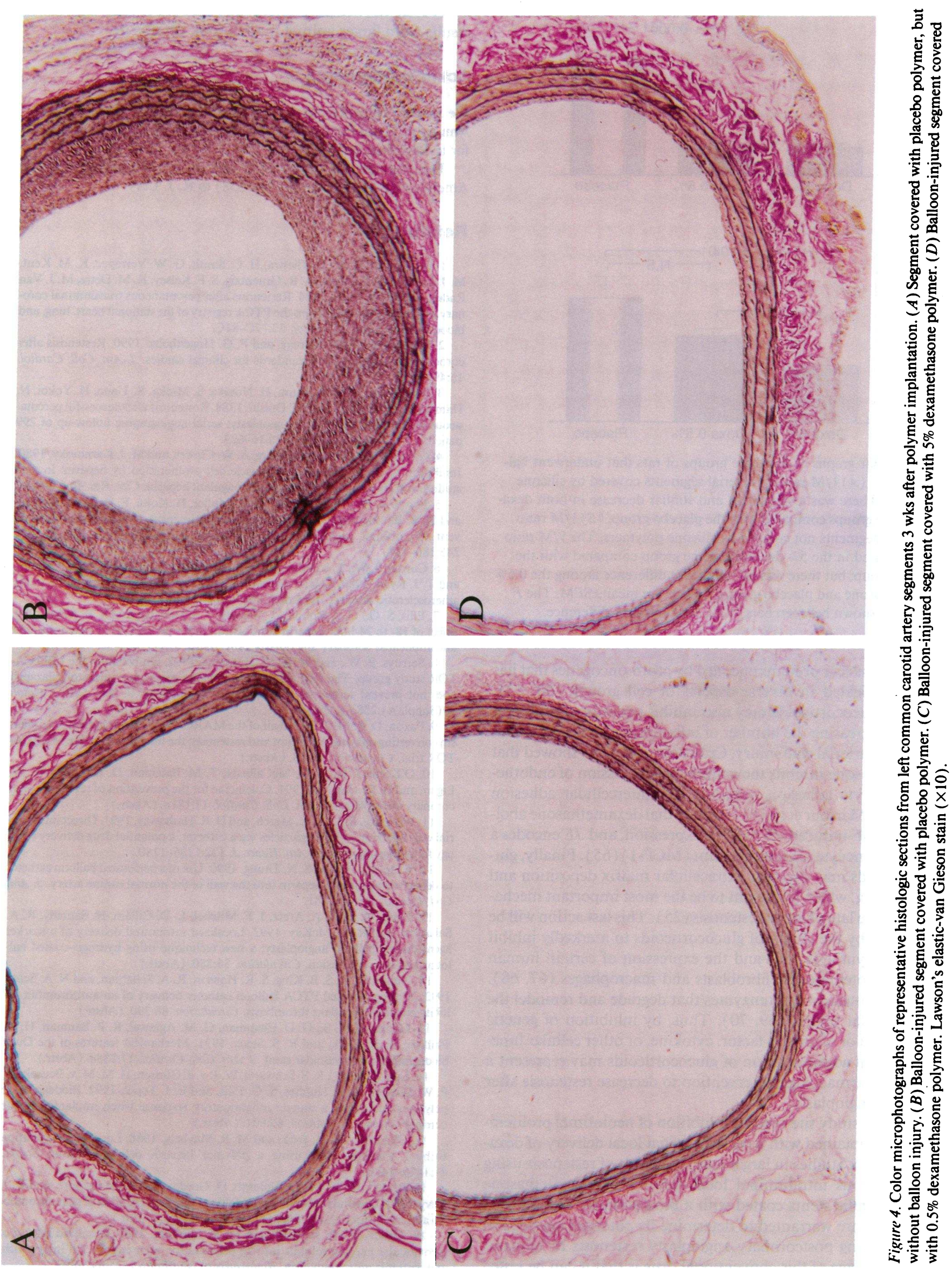
A

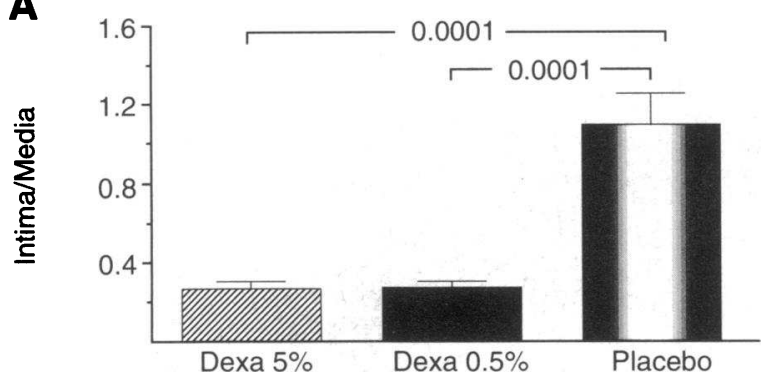

B

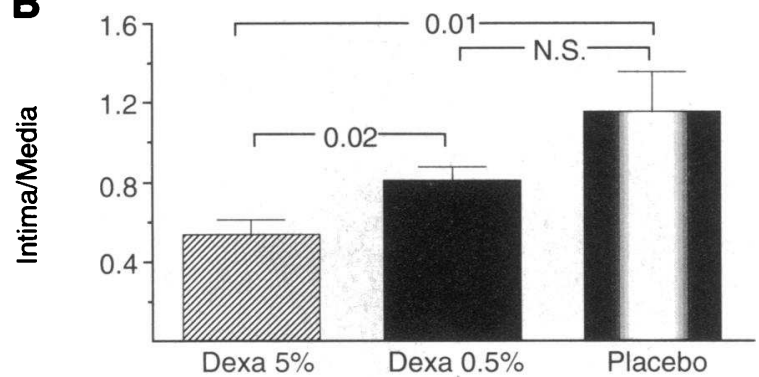

Figure 5. Bar graphs of the three groups of rats that underwent balloon injury. $(A) \mathrm{I} / \mathrm{M}$ ratio of arterial segments covered by silicone polymers. There was a significant and similar decrease in both dexamethasone groups compared with the placebo group. (B) I/M ratio of arterial segments not covered by silicone polymers. The I/M ratio was decreased in the 5\% dexamethasone group compared with the placebo group, but there was no significant difference among the $0.5 \%$ dexamethasone and placebo groups. Values are mean \pm SEM. The $P$ values are shown between bars. N.S., no significant difference.

a class of nuclear proteins encoded by proto-oncogenes that has been implicated in diverse aspects of cell growth $(60,63)$. Fourth, glucocorticoids may also inhibit neointimal proliferation by decreasing the number of inflammatory cells present at the site of arterial wall injury. Cronstein et al. (64) showed that dexamethasone inhibits the endothelial expression of endothelial leukocyte adhesion molecule and intercellular adhesion molecule. Marmur et al. (65) showed that dexamethasone abolishes PDGF-induced $J E$ mRNA expression, and $J E$ encodes a potent monocyte chemoattractant (MCP-1) (65). Finally, glucocorticoids may decrease extracellular matrix deposition and remodeling, which is thought to be the most important mechanism of the late phase of restenosis (25). This last action will be mediated by the ability of glucocorticoids to markedly inhibit collagen synthesis (66) and the expression of certain human metalloproteinases by fibroblasts and macrophages $(67,68)$. Metalloproteinases are enzymes that degrade and remodel the extracellular matrix $(69,70)$. Thus, by inhibition of genetic expression or of growth factor, cytokine, or other cellular functions, local administration of glucocorticoids may represent a potent pharmacologic intervention to decrease restenosis after balloon angioplasty.

In this study site-specific inhibition of neointimal proliferation was obtained with a periadventitial local delivery of dexamethasone. Studies in larger animal models of restenosis using percutaneous intraluminal local delivery of dexamethasone (i.e., metallic stents coated with a bioabsorbable eluting drug polymer) are warranted to determine its potential application in inhibiting postcoronary angioplasty restenosis in humans. An advantage of this conventional drug is that it can be tested directly in restenosis clinical trials using intraluminal local delivery systems (i.e., porous balloon catheters or coated stents) if results from larger animal models look promising.

\section{Acknowledgments}

We thank Joseph Trachy (University of Michigan Medical School, Ann Arbor), and Farhad Faroudi (The Cleveland Clinic Foundation) for technical assistance.

This research was supported in part by a Grant-in-Aid from the American Heart Association (91-1538) to R. J. Levy.

\section{References}

1. Holmes, D. R., R. E. Vliestra, H. C. Smith, G. W. Vetrovec, K. M. Kent, M. J. Cowley, D. P. Faxon, A. R. Gruentzig, S. F. Kelsey, K. M. Detre, M. J. Van Raden, and M. B. Molk. 1984. Restenosis after percutaneous transluminal coronary angioplasty: a report from the PTCA registry of the national heart, lung, and blood institute. Am. J. Cardiol. 53:77C-81C.

2. Beatt, K. J., P. W. Serruys, and P. G. Hugenholtz. 1990. Restenosis after coronary angioplasty: New standards for clinical studies. J. Am. Coll. Cardiol. 15:491-498.

3. Nobuyoshi, M., T. Kimura, H. Nosaka, S. Mioka, K. Ueno, H. Yokoi, N. Hamasaki, H. Horiuchi, and H. Onishi. 1988. Restenosis after successful percutaneous transluminal coronary angioplasty: serial angiographic follow-up of 299 patients. J. Am. Coll. Cardiol. 12:616-623.

4. Guyton, J. R., R. D. Rosenberg, A. W. Clowes, and M. J. Karnovsky. 1980. Inhibition of rat arterial smooth muscle cell proliferation by heparin: in vivo studies with anticoagulant and nonanticoagulant heparin. Circ. Res. 46:625-634.

5. Powell, J. S., J. P. Clozel, R. K. M. Muller, H. Kuhn, F. Hefti, M. Hosang, and H. R. Baumgartner. 1989. Inhibitors of angiotensin-converting enzyme prevent myointimal proliferation after vascular injury. Science (Wash. DC). 245:186-188.

6. Currier, J. W., T. K. Pow, A. C. Minihan, C. C. Haudenschild, D. P. Faxon, and T. J. Ryan. 1989. Colchicine inhibits restenosis after iliac angioplasty in the atherosclerotic rabbit. Circulation. 80(Suppl. II):66. (Abstr.)

7. Ellis, S. G., G. S. Roubin, J. Wilentz, J. S. Douglas, and S. B. King. 1989. Effect of 18- to 24-hour heparin administration for prevention of restenosis after uncomplicated coronary angioplasty. Am. Heart. J. 117:777-82.

8. Serruys, P. W., and W. R. M. Hermans. 1992. On behalf of the MERCATOR study group. The new angiotensin converting enzyme inhibitor cilazapril does not prevent restenosis after coronary angioplasty. J. Am. Coll. Cardiol. 19(Suppl. A):258a. (Abstr.)

9. Faxon, D. P. 1992. On behalf of the MARCATOR investigators. Angiotensin converting enzyme inhibition and restenosis: the final results of the MARCATOR trial. Circulation. 86:53. (Abstr.)

10. O'Keefe, J. H., B. D. McCallister, T. M. Bateman, D. Kuhnlein, R. W. Ligon, and G. O. Hartzler. 1991. Colchicine for the prevention of restenosis after coronary angioplasty. J. Am. Coll. Cardiol. 17:181a. (Abstr.)

11. Wilensky, R. L., K. L. March, and D. R. Hathaway. 1991. Direct intraarterial wall injection of microparticles via a catheter: a potential drug delivery strategy following angioplasty. Am. Heart. J. 122:1136-1140.

12. Wolinsky, H., and S. N. Thung. 1990. Use of a perforated balloon catheter to deliver concentrated heparin into the wall of the normal canine artery. J. Am. Coll. Cardiol. 15:475-481.

13. Fram, D. B., T. A. Aretz, J. F. Mitchel, L. D. Gillam, H. Samady, R. A. Sahatjian, and R. G. McKay. 1992. Localized intramural delivery of a marker agent during balloon angioplasty: a new technique using hydrogel-coated balloons and active diffusion. Circulation. 86:380. (Abstr.)

14. Nunes, G. L., S. B. King, S. R. Hanson, R. A. Sahatjian, and N. A. Scott. 1992. Hydrogel-coated PTCA balloon catheter delivery of an antithrombin inhibits platelet-dependent thrombosis. Circulation. 86:380. (Abstr.)

15. Gammon, R. S., G. D. Chapman, G. M. Agrawal, R. P. Bauman, H. R. Phillips, H. G. Clark, and R. S. Stack. 1991. Mechanical features of the Duke biodegradable intravascular stent. J. Am. Coll. Cardiol. 17:235a. (Abstr.)

16. Lincoff, A. M., R. S. Schwartz, W. J. v. d. Giessen, H. M. M. v. Beusekom, P. W. Serruys, D. R. Holmes, S. G. Ellis, and E. J. Topol. 1992. Biodegradable polymers can evoke a unique inflammatory response when implanted in the coronary artery. Circulation. 86:801. (Abstr.)

17. Okada, T., D. H. Bark, and M. R. Mayberg. 1988. Local anticoagulation without systemic effect using a polymer heparin delivery system. Stroke. 19:1470-1476.

18. Muller, D. W. M., G. Golomb, D. Gordon, J. M. Maraganore, and R. J. Levy. 1992. Local adventitial hirulog delivery for the prevention of stent thrombosis and neointimal thickening. Circulation. 86:381. (Abstr.)

19. Okada, T., D. H. Bark, and M. R. Mayberg. 1989. Localized release of perivascular heparin inhibits intimal proliferation after endothelial injury without systemic anticoagulation. Neurosurgery (Baltimore). 25:892-898. 
20. Edelman, E. R., D. H. Adams, and M. J. Karnovsky. 1989. Effect of controlled adventitial heparin delivery on smooth muscle cell proliferation following endothelial injury. Proc. Natl. Acad. Sci. USA. 87:3773-3777.

21. Golomb, G., M. Dixon, M. S. Smith, F. J. Schoen, and R. J. Levy. 1987 Controlled-release drug delivery of diphosphonates to inhibit bioprosthetic heart valve calcification: release rate modulation with silicone matrices via drug solubility and membrane coating. J. Pharm. Sci. 76:271-276.

22. Parrillo, J. E., and A. S. Fauci. 1979. Mechanisms of glucocorticoid action on immune processes. Annu. Rev. Pharmacol. Toxicol. 19:179-201.

23. Austin, G. E., N. B. Ratliff, J. Hollman, S. Tabei, and D. F. Phillips. 1985 Intimal proliferation of smooth muscle cells as an explanation for recurrent coronary artery stenosis after percutaneous transluminal coronary angioplasty. J. Am Coll. Cardiol. 6:369-375.

24. Cole, C. W., P. O. Hagen, J. F. Lucas, E. M. Mikat, M. K. O’Malley, Z. S. Radic, R. G. Makhoul, and R. L. McCann. 1987. Association of polymorphonuclear leukocytes with sites of aortic catheter-induced injury in rabbits. Atherosclerosis. 67:229-236.

25. Forrester, J. S., M. Fishbein, R. Helfant, and J. Fagin. 1991. A paradigm for restenosis based on cell biology: clues for the development of new preventive therapies. J. Am. Coll. Cardiol. 17:758-69.

26. MacDonald, R. G., R. S. Panush, and C. J. Pepine. 1987. Rationale for use of glucocorticoids in modification of restenosis after percutaneous transluminal coronary angioplasty. Am. J. Cardiol. 60:56B-60B.

27. Libby, P. 1992. Do vascular wall cytokines promote atherogenesis? Hosp. Prac. 27:51-58.

28. Longenecker, J. P., L. A. Kilty, and L. K. Johnson. 1982. Glucocorticoid influence on growth of vascular wall cells in culture. J. Cell. Physiol. 113:197202.

29. Jarvelainen, H., T. Halme, and T. Ronnemaa. 1982. Effect of cortisol on the proliferation and protein synthesis of human aortic smooth muscle cells in culture. Acta Med. Scand. Suppl. 660:114-122.

30. Nichols, N. R., C. A. Olsson, and J. W. Funder. 1983. Steroid effects on protein synthesis in cultured smooth muscle cells from rat aorta. Endocrinology. 113:1096-1101.

31. Manthorpe, R., C. Garbarsch, and I. Lorenzen. 1975. Glucocorticoid effect on repair processes in vascular connective tissue. Acta Endocrinol. 80:380 397.

32. Gordon, J. B., B. C. Berk, M. A. Bettmann, A. P. Selwyn, H. Rennke, and R. W. Alexander. 1987. Vascular smooth muscle proliferation following balloon Injury is synergistically inhibited by low molecular weight heparin and hydrocortisone. Circulation. 76(Suppl. IV):213. (Abstr.)

33. Hassenstein, S., H. Hanke, M. Oberhoff, M. Schneider, J. Kamenz, R. Rieben, E. Betz, and K. R. Karsch. 1992. Impact of dexamethasone treatment in the peri- and postintervention period after balloon angioplasty. Eur. Heart. J. 13:29. (Abstr.)

34. Levy, R. J., J. Wolfrum, F. J. Schoen, M. A. Hawley, S. A. Lund, and R. Langer. 1985. Inhibition of calcification of bioprosthetic heart valves by loca controlled-release diphosphonate. Science (Wash. DC). 228:190-192.

35. Levy, R. J., T. P. Johnston, A. Sintov, and G. Golomb. 1990. Controlled release implants for cardiovascular disease. J. Controlled Release. 11:245-254.

36. Gebrane, J., J. Roland, and L. Orcel. 1982. Experimental diffuse intima thickening of the femoral arteries in the rabbit. Virchows Arch. A Pathol. Anat. Histol. 396:41-59.

37. Betz, E., P. Fallier-Becker, K., Wolburg-Buchholz, and Z. Folev. 1991. Proliferation of smooth muscle cells in the inner and outer layers of the tunica media of arteries. J. Cell. Physiol. 147:385-395.

38. Martin, J. F., R. F. G. Booth, and S. Moncada. 1990. Arterial wall hypoxia following hypoperfusion through the vasa vasorum is an initial lesion in atherosclerosis. Eur. J. Clin. Invest. 20:588-592.

39. Barker, S. G. E., A. Talbert, C. S., P. A. Baskerville, and J. F. Martin. 1993. Arterial intimal hyperplasia after occlusion of the adventitial vasa vasorum in the pig. Arterioscler. Thromb. 13:70-77.

40. VanLierde, J., M. C. Vrolix, I. K. DeScheerder, Z. Wu, J. H. Piessens, and H. DeGeest. 1991. Feasibility of transient delivery of ridogrel via microporous balloon technique in normal canine arteries. Circulation. 84:296. (Abstr.)

41. Muller, D. W. M., E. J. Topol, G. Abrams, K. Gallagher, and S. G. Ellis. 1992. Intramural methotrexate therapy for the prevention of neointimal thickening after balloon angioplasty. J. Am. Coll. Cardiol. 20:460-466.

42. Wilensky, R. L., I. Gradus-Pizlo, K. L. March, G. E. Sandusky, and D. R. Hathaway. 1992. Efficacy of local intramural injection of colchicine in reducing restenosis following angioplasty in the atherosclerotic rabbit model. Circulation. 86:52. (Abstr.)

43. Sintov, A., W. Scott, M. Dick, and R. J. Levy. 1988. Cardiac controlled release for arrhythmia therapy: lidocaine-polyurethane matrix studies. J. Controlled Release. 8:157.

44. Johnston, T. P., J. A. Boyd, B. L. Ciesliga, F. J. Schoen, G. Amidon, and R. J. Levy. 1990. Controlled release of ethanehydroxy diphosphonate from polyurethane reservoirs to inhibit calcification of bovine pericardium used in bioprosthetic heart valves. Int. J. Pharm. (Amst.). 59:95-104.

45. Bolling, S. F., H. Lin, T. M. Annesley, J. A. Boyd, K. P. Gallagher, and
R. J. Levy. 1991. Local cyclosporine immunotherapy of cardiac transplant in rats enhances survival. J. Heart Lung Transplant. 10:577-583.

46. Olanof, L. S., J. M. Anderson, and R. D. Jones. 1979. Sustained release of gentamicin from prosthetic heart valves. Trans. Am. Soc. Artif. Intern. Organs. 25:334-338.

47. Mond, H., K. Stokes, J. Holland, L. Griggs, P. Kertes, B. Pate, and K. D. Hunt. 1988. The porous titanium steroid eluting electrode: a double blind study assessing the stimulation threshold effects of steroid. PACE. 11:214-219.

48. Edelman, E. R., M. A. Nugent, L. T. Smith, and M. J. Karnovsky. 1992. Basic fibroblast growth factor enhances the coupling of intimal hyperplasia and proliferation of vasa vasorum in injured rat arteries. J. Clin. Invest. 89:465-473.

49. Edelman, E. R., M. A. Nugent, and M. J. Karnovsky. 1993. Perivascular and intravenous administration of basic fibroblast growth factor: Vascular and solid organ deposition. Proc. Natl. Acad. Sci. USA. 90:1513-1517.

50. Simons, M., E. R. Edelman, J.-L. DeKeyser, R. Langer, and R. D. Rosenberg. 1992. Antisense c-myb oligonucleotides inhibit intimal arterial smooth muscle cell accumulation in vivo. Nature (Lond.). 359:67-70.

51. Crabbe, P., S. Archer, G. Benagiano, E. Diczfalusy, C. Djerassi, J. Fried, and T. Higuchi. 1983. Long-acting contraceptive agents: design of the WHO chemical synthesis program. Steroids. 41:243-253.

52. Berk, B. C., and E. W. Raines. 1989. Vascular smooth muscle growth inhibition by hydrocortisone is associated with decreased PDGF A chain expression. FASEB (Fed. Am. Soc. Exp. Biol.) J. 3:611a. (Abstr.)

53. Berk, B. C., and G. N. Rao. 1993. Angiotensin II-induced vascular smooth muscle cell hypertrophy: PDGF A-Chain mediates the increase in cell size. $J$. Cell. Physiol. 154:368-380.

54. Ross, R., and J. A. Glomset. 1976. The pathogenesis of atherosclerosis. $N$ Engl. J. Med. 295:369-377.

55. Ferns, G. A. A., E. W. Raines, K. H. Sprugel, A. S. Motani, M. A. Reidy, and $\mathbf{R}$. Ross. 1991. Inhibition of neointimal smooth muscle cell accumulation after angioplasty by an antibody to PDGF. Science (Wash. DC). 253:1129-1132.

56. Lee, S. W., A.-P. Tsou, H. Chan, J. Thomas, K. Petrie, E. M. Eugui, and A. C. Allison. 1988. Glucocorticoids selectively inhibit the transcription of the interleukin $1 \beta$ gene and decrease the stability of interleukin $1 \beta$ mRNA. Proc. Natl. Acad. Sci. USA. 85:1204-1208.

57. Libby, P., S. Warner, and G. Friedman. 1988. Interleukin 1: a mitogen for human vascular smooth muscle cells that induces the release of growth-inhibitory prostanoids. J. Clin. Invest. 81:487-498.

58. Raines, E. W., S. K. Dower, and R. Ross. 1989. Interleukin-1 mitogenic activity for fibroblasts and smooth muscle cells is due to PDGF-AA. Science (Wash. DC). 243:393-396.

59. Gay, C. G., and J. A. Winkles. 1991. Interleukin 1 regulates heparin-binding growth factor 2 gene expression in vascular smooth muscle cells. Proc. Natl. Acad. Sci. USA. 88:296-300.

60. Schule, R., P. Rangarajan, S. Kliewer, L. J. Ransone, J. Bolado, N. Yang, I. M. Verma, and R. M. Evans. 1990. Functional antagonism between oncoprotein C-Jun and the glucocorticoid receptor. Cell. 62:1217-1226.

61. Jonat, C., H. J. Rahmsdorf, K.-k. Park, A. C. B. Cato, S. Gebel, H. Ponta, and P. Herrlich. 1990. Antitumor promotion and antinflammation: down-modulation of AP-1 (Fos/Jun) activity by glucocorticoid hormone. Cell. 62:11891204.

62. Hass, R., M. Brach, S. Kharbanda, G. Giese, P. Traub, and D. Kufe. 1991. Inhibition of phorbol ester-induced monocytic differentiation by dexamethasone is associated with down-regulation of C-Fos and C-Jun (AP-1). J. Cell. Physiol. 149:125-131.

63. Curran, T., and B. R. Franza. 1988. Fos and Jun: The AP-1 connection. Cell. 55:395-397.

64. Cronstein, B. N., S. C. Kimmel, R. I. Levin, and F. Martiniuk. 1991. A mechanism for the antiinflammatory effects of corticosteroids: the glucocorticoid receptor regulates leukocyte adhesion to endothelial cells and expression of endothelial-leukocyte adhesion molecule 1 and intercellular adhesion molecule 1. Proc. Natl. Acad. Sci. USA. 89:9991-9995.

65. Marmur, J. D., M. Poon, M. Rossikhina, and M. B. Taubman. 1992 Induction of PDGF-responsive genes in vascular smooth muscle. Circulation. 86:53-60.

66. Krane, S. M., and E. P. Amento. 1984. Glucocorticoids and collagen disease. Adv. Exp. Med. Biol. 171:61-71.

67. Shapiro, S. D., E. J. Campell, D. K. Kobayashi, and H. G. Welgus. 1991. Dexamethasone selectively modulates basal and lipopolysaccharide-induced metalloproteinase and tissue inhibitor of metalloproteinase production by human alveolar macrophages. J. Immunol. 146:2724-2729.

68. Clark, S. D., D. K. Kobayashi, and H. G. Welgus. 1987. Regulation of the expression of tissue inhibitor of metalloproteinases and collagenase by retinoids and glucocorticoids in human fibroblasts. J. Clin. Invest. 80:1280-1288.

69. Welgus, H. G., E. J. Campbell, J. D. Cury, A. Z. Eisen, R. M. Senior, S. M Wilhelm, and G. I. Golberg. 1990. Neutral metalloproteinases produced by human macrophages: enzyme profile, regulation, and expression during cellular development. J. Clin. Invest. 86:1496-1502.

70. Muller, D., B. Quantin, M. C. Gesnel, R. Millon-Collard, J. Abecassis, and R. Breathnach. 1988. The collagenase gene family in humans consists of at least four members. Biochem. J. 253:187-192. 